\title{
BEST POSSIBLE INEQUALITIES BETWEEN GENERALIZED LOGARITHMIC MEAN AND WEIGHTED GEOMETRIC MEAN OF GEOMETRIC, SQUARE-ROOT, AND ROOT-SQUARE MEANS
}

\section{LiU CHUNRONG AND LIU SiQI}

Abstract. We establish two optimal double inequalities among generalized logarithmic mean $L_{p}(a, b)$, geometric mean $G(a, b)$, square-root $N(a, b)$, and root-square mean $S(a, b)$.

Mathematics subject classification (2010): 26D15, 26D20.

Keywords and phrases: Inequality, generalized logarithmic mean, geometric mean, square-root mean, root-square mean.

\section{REFERENCES}

[1] A. A. K. Abuhany, S. R. Salem, And I. M. Salman, On Steffensen's integral inequality with applications, Journal of Rajasthan Academy of Physical Sciences, 5, 1 (2006), 1-12.

[2] H. Alzer And W. Janous, Solution of problem $8^{*}$, Crux Mathematicorum with Mathematical Mayhem, 13 (1987), 173-178.

[3] P. S. Bullen, D. S. Mitrinović, And P. M. Vasić, Means and Their Inequalities, Volume 31, D. Reidel, Dordrecht, The Netherlands, 1988.

[4] CH.-P. Chen AND F. QI, Monotonicity properties for generalized logarithmic means, The Australian Journal of Mathematical Analysis and Applications, 1, 2 (2004), article 2, p. 499.

[5] CH.-P. CHEN, The monotonicity of the ratio between generalized logarithmic means, Journal of Mathematical Analysis and Applications, 345, 1 (2008), 86-89.

[6] B. C. CARLson, The logarithmic mean, The American Mathematical Monthly, 79 (1972), 615-618.

[7] Yu-Ming Chu And Bo-Yong Long, Best possible inequalities between generalized logarithmic mean and classical means, Abstract and Applied Analysis, 2010, Article ID 303286, 13 pages.

[8] P. Kahlig And J. MatKowski, Functional equations involving the logarithmic mean, Zeitschrift für Angewandte Mathematik und Mechanik, 767 (1996), 385-390.

[9] E. B. LEACH AND M. C. ShOlAnder, Extended mean values II, Journal of Mathematical Analysis and Applications, 92, 1 (1983), 207-223.

[10] B. Y. Long And Y. M. Chu, Optimal Inequalities for Generalized Logarithmic, Arithmetic, and Geometric Means, Journal of Inequalities and Applications, 2010, Article ID 806825, 10 pages.

[11] B. Mond, C. E. M. Pearce, And J. PeČArić, The logarithmic mean is a mean, Mathematical Communications, 2, 1 (1997), 35-39.

[12] Q. J. MAO, Powermean, logarthimicmean and Heronian dual mean of two positive number, Journal of Suzhou College of Education, 16, 1-2 (1999), 82-85.

[13] N. S. NAdirashVili, New isoperimetric inequalities in mathematical physics, in Partial Differential Equations of Elliptic Type (Cortona, 1992), Sympos. Math., XXXV, pp. 197-203, Cambridge University Press, Cambridge, UK, 1994.

[14] A. O. Pittenger, The logarithmic mean in $n$ variables, The American Mathematical Monthly, 92, 2 (1985), 99-104.

[15] G. Pólya AND G. SZEgö, Isoperimetric Inequalities in Mathematical Physics, Princeton University, Princeton, NJ, USA, 1951.

[16] F. QI, SH.-X. CHEN, AND CH.-P. CHEN, Monotonicity of ratio between the generalized logarithmic means, Mathematical Inequalities \& Applications, 10, 3 (2007), 559-564. 
[17] F. QI, X.-A. LI, AND SH.-X. Chen, Refinements, extensions and generalizations of the second Kershaw's double inequality, Mathematical Inequalities \& Applications, 11, 3 (2008), 457-465.

[18] K. B. StOlARsky, The power and generalized logarithmic means, The American Mathematical Monthly, 87, 7 (1980), 545-548.

[19] H.-N. SHI, Schur-convex functions related to hadamard-type inequalities, Journal of Mathematical Inequalities, 1, 1 (2007), 127-136.

[20] J. SÁNDOR, A note on some inequalities for means, Archiv der Mathematik, 56, 5 (1991), 471-473. 